\title{
EFFECT OF PHYSICAL ACTIVITY ON BLOOD SUGAR AND CORTISOL LEVEL AMONG THE ELDERLY WITH DEPRESSION IN SEMARANG, CENTRAL JAVA
}

\author{
Arwani \\ School of Health Polytechnics, Ministry of Health Semarang
}

\begin{abstract}
Background: Major depression have been shown in earlier studies to be associated with cortisol changes in old depressed patients. A positive correlation was also demonstrated between cortisol levels and physical capacity. Previous studies suggest that physical capacity modulates the relationship between depression and cortisol levels. This study aimed to examine effect of physical activity on blood sugar and cortisol level among the elderly with depression in Semarang, Central Java.

Subjects and Method: This was a non-randomized controlled trial conducted at Puskesmas (Community Health Center) Srondol, Semarang, Central Java. A total of 20 elderlies aged $\geq 65$ years with depression were allocated into 10 elderlies in the experimental group and 10 in the control group. The dependent variable was blood sugar and cortisol levels. The independent variable was physical activity. This physical activity included a slow walk 20 to 30 minutes per day for a week. The data were taken from the medical record and analyzed by independent t-test.

Results: The declines in the blood sugar level and the increases in cortisol level before and after intervention between the experimental (physical activity) group and the control group were comparable and statistically non-significant. However, this finding may have been confounded by unadjusted effect of dietary intake or the physical activity was not rigorous enough to make changes both in blood sugar and cortisol levels.

Conclusion: The incremental physical activity was not effective in making changes in blood sugar and cortisol among the elderly with depression. However, this may due to some confounding by the unadjusted effect of dietary intake and negligible physical activity.
\end{abstract}

Keywords: blood sugar, blood cortisol, physical activity, depression, elderly.

\section{Correspondence:}

Arwani. School of Health Polytechnics, Ministry of Health Semarang, Central Java, Semarang, Central Java. Email: arwani_arwani@ymail.com.

Mobile: 08122523964

The 4th International Conference on Public Health

Best Western Premier Hotel, Solo, Indonesia, August 29-30, 2018 | 295

https://doi.org/10.26911/theicph.2018.05.09 